Published in final edited form as:

Am J Obstet Gynecol. 2014 April ; 210(4): 328.e1-328.e5. doi:10.1016/j.ajog.2013.11.011.

\title{
Association of Cord Blood Digitalis-Like Factor and Necrotizing Enterocolitis
}

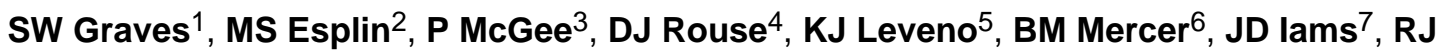 \\ Wapner $^{8}$, Y Sorokin ${ }^{9}$, JM Thorp ${ }^{10}$, SM Ramin ${ }^{11}$, FD Malone ${ }^{12}$, MJ O'Sullivan ${ }^{13}$, AM \\ Peaceman $^{14}$, GD Hankins ${ }^{15}$, DJ Dudley ${ }^{16}$, SN Caritis ${ }^{17}$, and for the Eunice Kennedy Shriver \\ National Institute of Child Health and Human Development Maternal-Fetal Medicine Units \\ Network, Bethesda, MD \\ ${ }^{1}$ Department of Chemistry and Biochemistry, Brigham Young University, Provo, UT \\ ${ }^{2}$ Departments of Obstetrics and Gynecology, Utah Health Science Center, Salt Lake City, UT
}

\begin{abstract}
(C) 2013 Mosby, Inc. All rights reserved.
Corresponding Author: Steven W. Graves, Ph.D., Department of Chemistry and Biochemistry, BNSN C212, Brigham Young University, Provo, UT 84602, swgraves@chem.byu.edu, Tel \#: 801 422-2148, FAX \#: 801 422-0153.
\end{abstract}

Publisher's Disclaimer: This is a PDF file of an unedited manuscript that has been accepted for publication. As a service to our customers we are providing this early version of the manuscript. The manuscript will undergo copyediting, typesetting, and review of the resulting proof before it is published in its final citable form. Please note that during the production process errors may be discovered which could affect the content, and all legal disclaimers that apply to the journal pertain.

Disclosure Statement: The authors report no conflict of interest.

In addition to the authors, other members of the Eunice Kennedy Shriver National Institute of Child Health and Human Development Maternal-Fetal Medicine Units Network are as follows:

University of Alabama at Birmingham, Birmingham, AL - J.C. Hauth, A. Northen, T. Hill-Webb, S. Tate, K. Nelson, F. Biasini University of Utah, Salt Lake City, UT - M. Varner, L. Fullmer, K. Anderson, A. Guzman, M. Jensen, L. Williams

University of Texas Southwestern Medical Center, Dallas, TX - M.L. Sherman, J. Dax, L. Faye-Randall, C. Melton, E. Flores

Case Western Reserve University-MetroHealth Medical Center, Cleveland, $\mathrm{OH}$ - M. Collin, G. VanBuren, C. Milluzzi, M. Fundzak, C. Santori

The Ohio State University, Columbus, $\mathrm{OH}$ - F. Johnson, M.B. Landon, C. Latimer, V. Curry, S. Meadows

Thomas Jefferson University, Philadelphia, PA - A. Sciscione, M.M. DiVito, M. Talucci, S. Desai, D. Paul

University of Tennessee, Memphis, TN - B.M. Sibai, R. Ramsey, W. Mabie, L. Kao, M. Cassie

Wayne State University, Detroit, MI - G.S. Norman, D. Driscoll, B. Steffy, M.P. Dombrowski

Wake Forest University Health Sciences, Winston-Salem, NC - P.J. Meis, M. Swain, K. Klinepeter, M. O'Shea, L. Steele

University of North Carolina at Chapel Hill, Chapel Hill - K.J. Moise, Jr., S. Brody, J. Bernhardt, K. Dorman

University of Texas Health Science Center at Houston-Children's Memorial Hermann

Hospital, Houston, TX - L.C. Gilstrap, III, M.C Day, E. Gildersleve, F. Ortiz, M. Kerr

Columbia University, New York, NY - V. Pemberton, L. Paley, C. Paley, S. Bousleiman, V. Carmona

Brown University, Providence, RI - M. Carpenter, J. Tillinghast, D. Allard, B. Vohr, L. Noel, K. McCarten

University of Cincinnati, Cincinnati, $\mathrm{OH}-\mathrm{M}$. Miodovnik, N. Elder, W. Girdler, T. Gratton

University of Chicago, Chicago, IL - A.H. Moawad, M. Lindheimer, P. Jones

University of Miami, Miami, FL- F. Doyle, C. Alfonso, M. Scott, R. Washington

Northwestern University, Chicago, IL - G. Mallett, M. Ramos-Brinson., P. Simon

University of Texas Medical Branch, Galveston, TX - T. Wen, L.A. Goodrum, G.R. Saade, G.L. Olson, H.M. Harirah, E. Martin

University of Texas at San Antonio, San Antonio, TX - E. Xenakis, D. Conway, M. Berkus

University of Pittsburgh, Pittsburgh, PA - T. Kamon, M. Cotroneo, C. Milford

The George Washington University Biostatistics Center - S.J. Weiner, B. Jones-Binns, M. Cooney, M. Fischer, S. McLaughlin, K. Brunette, E. Fricks

National Institute of Neurological Disorders and Stroke, Bethesda, MD - D. Hirtz, K.B.

Nelson Eunice Kennedy Shriver National Institute of Child Health and Human Development, Bethesda, MD - S. Tolivaisa, D.

McNellis, C. Catz, K. Howell

MFMU Network Steering Committee Chair (University of Pittsburgh, Pittsburgh, PA) - J. Roberts

CONDENSATION

An endogenous sodium pump inhibitor was increased in the cord serum of infants who later developed necrotizing enterocolitis

compared with infants who did not. 


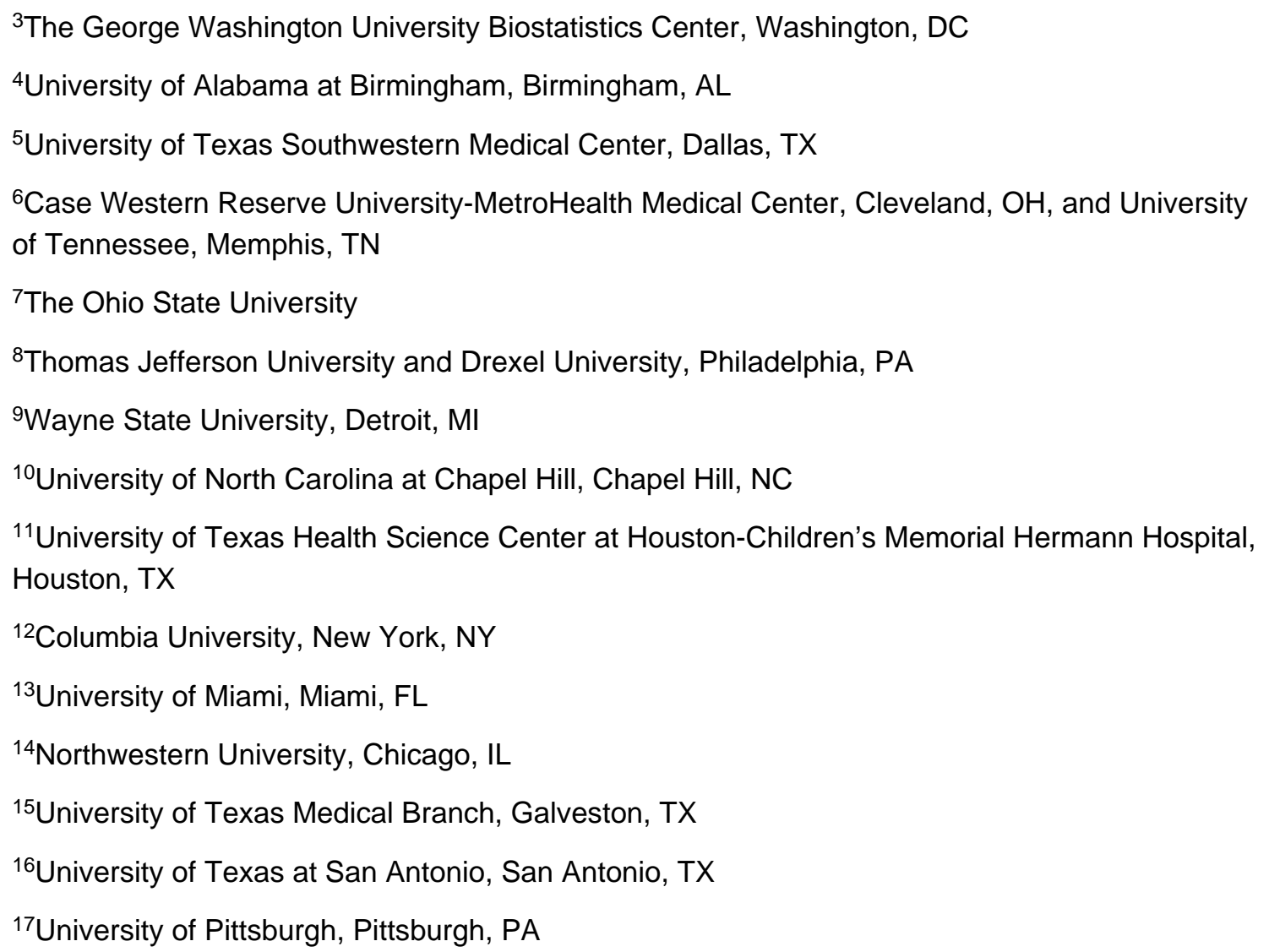

\section{Abstract}

Objective-Endogenous digoxin-like factor (EDLF) has been linked to vasoconstriction, altered membrane transport and apoptosis. Our objective was to determine whether increased EDLF in the cord sera of preterm infants was associated with an increased incidence of necrotizing enterocolitis (NEC).

Methods-Cord sera from pregnant women enrolled in a randomized trial of $\mathrm{MgSO}_{4}$ for fetal neuroprotection were analyzed for EDLF using a red cell $\mathrm{Rb}^{+}$uptake assay where inhibition of sodium pump-mediated $\mathrm{Rb}^{+}$transport was used as a functional assay of EDLF. Specimens were assayed blinded to neonatal outcome. Cases (NEC, $n=25$ ) and controls (neonates not developing stage 2 or 3 NEC, $n=24$ ) were matched by study center and gestational age. None of the women had preeclampsia. Cases and controls were compared using the Wilcoxon test for continuous and the Fisher's exact test for categorical variables. Conditional logistic regression analysis was used to assess the odds of case versus control by EDLF level.

Results-Cases and controls were not significantly different for gestational age (GA), race, maternal steroid use, premature rupture of membranes (PPROM) or $\mathrm{MgSO}_{4}$ treatment. In logistic models adjusted for treatment group, race, PPROM and GA, cord sera EDLF was significantly associated with development of NEC ( $\mathrm{p}=0.023)$.

Conclusions-These data demonstrated an association between cord sera EDLF and NEC. 


\section{Keywords}

necrotizing enterocolitis; pregnancy; sodium pump; digitalis-like factor; cord blood

\section{INTRODUCTION}

Early, preterm deliveries result in infants at risk for major medical complications and death $[1,2]$. Among the most serious problems is necrotizing enterocolitis (NEC) which represents a leading cause of neonatal mortality and morbidity $[3,4]$. NEC can be characterized by biochemical and morphologic changes, but the primary cause for this disease is poorly understood and the immediate mechanisms involved are not fully worked out. The incidence is inversely related to gestational age and birth weight [1].

NEC is characterized by one or more of the following: reduced bowel motility, bacterial infection, a marked inflammatory response perhaps representing activation of toll-like receptor 4, or difficulty in digestion (especially synthetic infant formula) which results in necrosis of a portion of the intestine [5-7]. It often occurs suddenly and progresses rapidly and can prove lethal. In severe cases, surgical resection of the bowel is required and this may result in long term complications, including neurodevelopmental deficits $[5,6]$.

Endogenously produced inhibitors of the sodium pump have been implicated in a number of diseases, especially hypertensive disorders [8-10]. It is also well documented that the endogenous digitialis-like factors (EDLFs) are present in the placenta [11-13], in cord serum [14] and in neonatal blood [14,15]. There is evidence that levels of these factors are proportionately higher in the neonatal circulation and cord blood the more premature the delivery $[14,15]$. The EDLFs by definition block ion transport and consequently nutrient transport coupled to the sodium pump, but can also cause apoptosis of exposed cells in a cell type and dose dependent manner [16-18]. Moreover, there is preliminary evidence that some complications of prematurity are reduced in response to antibody Fab treatment that targets EDLFs in the maternal circulation just prior to delivery [19]. Thus, we hypothesized that EDLFs may participate in NEC and that higher EDLF levels are associated with a higher incidence of NEC.

\section{MATERIALS AND METHODS}

\section{Patient Population}

Cord sera were obtained as part of a previously completed study, the Beneficial Effects of Antenatal Magnesium Sulfate (BEAM) Trial carried out under the auspices of the Eunice Kennedy Shriver National Institute of Child Health and Human Development Maternal-Fetal Medicine Units Network. This multicenter trial tested whether prophylactic magnesium sulfate given to women, for whom preterm delivery was imminent, reduced the risk of death or moderate to severe cerebral palsy in their children [20]. The study enrolled pregnant women presenting from 24.0 to 31.6 weeks gestation with advanced preterm labor, premature rupture of the membranes (pPROM) or indicated deliveries. Women were randomized to receive either intravenous magnesium sulfate or placebo. 
Cord sera analyzed in this nested case control study were selected by the MFMU Network's independent Biostatistics Center at George Washington University to produce a set of specimens matched for maternal characteristics. Specimens included cord sera from 28 neonate cases with NEC and 27 matched controls (by center and gestational age) selected for further analysis. Gestational age categories were the following: 24-26 weeks, 27-29 weeks, and 30-32 weeks. Cases were identified as women with a singleton pregnancy delivering prior to 32 weeks gestation, where the neonate experienced stage 2 or 3 NEC. Controls were mothers with the same characteristics but where the neonate was live born, survived to hospital discharge, and experienced no bronchopulminary dysplasia, severe necrotizing enterocolitis or IVH grades III or IV. Serum volume was sufficient to allow endogenous digitalis-like factors (EDLFs) levels to be obtained on 25 of the controls and 24 of the cases. Subjects with EDLF values between 0-2\% were reassigned a value of zero. Baseline characteristics are presented in Table 1. None of the selected subjects had preeclampsia. Researchers analyzing these specimens for EDLF were blinded to case or control status during the analysis and data evaluation.

\section{Measurement of Endogenous Digitalis-like Factor}

A functional assay of EDLF was used. This method has been described in detail [21]. The approach can be briefly summarized as follows: sodium pump (SP)-dependent $\mathrm{Rb}^{+}$uptake into red blood cells from non-pregnant, healthy controls is measured in the presence of serum from non-pregnant, healthy controls (as a negative, no inhibition control, i.e. maximal uptake) or in the presence of cord sera from the controls and cases studied. A known inhibitor of the SP, ouabain, is also added to a fraction of the same cells at a concentration $\left(10^{-3} \mathrm{M}\right)$ sufficient to inhibit SP-dependent $\mathrm{Rb}^{+}$uptake completely (positive control). The reduction in SP-dependent $\mathrm{Rb}^{+}$uptake is calculated as a percent of maximal SP dependent $\mathrm{Rb}^{+}$uptake. Note $\mathrm{Rb}^{+}$is not found in detectable levels in cells or the circulation but is an ion handled equivalently to $\mathrm{K}^{+}$, the natural substrate of the SP, allowing one to monitor uniquely the rate of the SP mediated $\mathrm{Rb}^{+}$entry as well as its specific inhibition. Using a $\mathrm{RbCl}$ standard of known concentration $(40.4 \mu \mathrm{g} / \mathrm{L})$, the relative standard deviation (RSD) within run was $1.46 \%$ and run-to-run was $2.67 \%$ [21]. The specimens were assayed in duplicate and the coefficient of variation for duplicates was $5.4 \%$.

\section{Statistical Analysis}

Fisher's Exact test and Wilcoxon's test were used to compare characteristics between categorical and continuous variables, respectively. The primary results are presented as medians with quartiles because of the skewness of the data, although means and standard errors the mean (SE) are also provided in the text. A conditional logistic regression was used to assess the odds of case/control status by EDLF level, adjusting for treatment group, race, PPROM, and stratified by gestational age (categorized as above) at delivery. In evaluating the two groups 23/25 of the cases and 22/24 of the controls experienced labor and hence labor status was not assessed in the statistical models. Finally, EDLF values were considered as a function of the severity of NEC using Spearman correlation analysis. All p-values were 2-sided. A p-value less than 0.05 was considered significant. 


\section{RESULTS}

There were no significant differences in maternal characteristics between women having premature infants who did not develop NEC and those who did (Table 1). All women with control infants and all the women with infants who developed NEC received steroids. By design none of the included specimens were obtained from pregnancies complicated by preeclampsia.

Also, neonatal characteristics were considered for cases and controls (See Table 2). None of the characteristics was significantly different, however, the length of hospitalization was on average $\sim 35$ days longer for infants with NEC ( $\mathrm{p}=0.058)$ as might be predicted.

\section{Association of NEC with cord serum EDLF}

The cord levels of ELDF in those infants developing NEC compared with control infants not developing major neonatal complications were significantly different (control median with quartiles: $11.95 \%(0,25.9)$ versus cases: $26.2 \%(16.2,51.6) \mathrm{EDLF}$ inhibition, $\mathrm{p}=0.0467$; means + SEM for these data sets are: controls, $16.1+3.7$ versus cases, $30.7+5.3 \%$ EDLF inhibition). See Figure 1. The distribution of these EDLF values for controls and cases is further described in Table 3. Cord serum EDLF was detectable by the assay in samples of all cases and in all but 3 of the controls. Cord serum EDLF levels were not statistically different between controls receiving active $\mathrm{Mg}^{2+}$ treatment compared with controls receiving placebo. This was also true for NEC positive cases (Data not shown).

Based on a conditional logistic model adjusting for treatment group, race, PPROM, and stratified by gestational age category at delivery, the EDLF level was significantly associated with NEC ( $\mathrm{p}=0.0233$ ). For a 10 unit increase in EDLF, the odds of stage 2 or 3 NEC increased by 1.49 (95\% CI: 1.06, 2.09). These results were similar to the unadjusted logistic model (OR for a 10 unit increase in EDLF of 1.46, 95\% CI: 1.05, 2.02, p=0.0229).

Additionally, when the severity of NEC was considered, EDLF levels were greater with more advanced disease, especially stage 3 NEC ( $p=0.008$; See Table 4).

\section{COMMENT}

Current understanding of the etiology of NEC is incomplete [3-7]. This study considered an additional factor in the development of NEC, an endogenous sodium pump inhibitor that has been implicated in a variety of disease pathways. It may influence both the fetus and later neonate given its presence in human placenta [11-13], cord sera [14] and neonatal blood $[14,15]$ with higher levels in premature infants $[14,15]$. Cord serum levels of EDLFs were significantly greater in those infants that later developed stage 2 or 3 NEC compared with infants who did not. While this is only an association, it raises the question of whether elevated levels of a sodium pump inhibitor could lead to changes in the neonate.

Historically studies have suggested a role for EDLFs in hypertension and renal disease [8]. Indeed, there is evidence that EDLFs may participate in preeclampsia [8-12]. For that reason we excluded women with preeclampsia from the current study. Additionally, more recent studies have demonstrated that sodium pump inhibitors can increase pro- 
inflammatory cytokines [22], cause arrest of cell division [18], activate apoptotic pathways [16-18] and lead to necrosis [23], all features of NEC. Hence, there is biological plausibility.

In this study, magnesium did not appear to have an effect on EDLF levels given that the portion of cases and controls receiving active $\mathrm{MgSO}_{4}$ therapy were comparable and direct comparison of cord EDLF levels in either controls or cases receiving active $\mathrm{MgSO}_{4}$ treatment did not differ respectively from controls or cases receiving placebo. Also, treatment arm was adjusted for in the multivariate model and there was still a significant association between EDLF and NEC. In retrospect it would have been interesting to know if EDLF levels in the mother's serum paralleled the results found in the cord sera of infants developing NEC compared with those who did not.

In considering these factors' possible participation in the development of NEC, it is recognized that the experiments conducted here do not answer that question directly. Samples from the infants themselves at the time of their complication were not available for EDLF analysis. Still, there was an increase in the odds ratio of developing NEC with an increase in cord serum EDLF level, raising the possibility of some type of interaction between the two parameters. Similarly, in more advanced NEC, EDLF levels were higher which is also consistent with a possible interaction between the two parameters.

There has been increased attention to the potential benefit of breast milk and rapid enteral feeding regimens [24-25], but the time to first feeding and the fraction of infants receiving breast were not recorded in the original study.

While some known activities of EDLF are found in NEC, the abnormalities observed are not uniquely produced by EDLFs and could be produced by several pathways. Consequently, while the results are interesting and potentially represent a contribution of EDLFs to NEC, additional, more detailed studies, are needed to clarify such questions now that a possible link has been found.

\section{Acknowledgments}

The authors thank Dr. Moana Hopoate-Sitake for performing all the laboratory experimentation.

The authors thank the following subcommittee members who participated in protocol development and coordination between clinical research centers (Allison T. Northen, M.S.N, R.N.), protocol/data management and statistical analysis (Steven Weiner, M.S. and Elizabeth Thom, Ph.D.), and protocol development and oversight (Deborah G. Hirtz, M.D. and Michael W. Varner, M.D.).

The project described was supported by grants from the Eunice Kennedy Shriver National Institute of Child Health and Human Development (NICHD) [HD27869, HD34208, HD34116, HD40544,HD27915, HD34136, HD21414, HD27917, HD27860, HD40560, HD40545, HD40485, HD40500, HD27905, HD27861, HD34122, HD40512, HD53907, HD34210, HD21410, HD36801, HD19897], MO1-RR-000080, and by the National Institute of Neurological Disorders and Stroke (NINDS) and does not necessarily represent the official views of the NICHD, NINDS, or the National Institutes of Health.

\section{REFERENCES}

1. Hack M, Fanaroff AA. Outcomes of children of extremely low birthweight and gestational age in the 1990's. Early Hum Dev. 1999; 53:193-218. [PubMed: 10088988] 
2. Groenendaal, f; Termote, JU.; van der Heide-Jalving, M., et al. Complications affecting preterm neonates from 1991 to 2006. What have we gained? Acta Paediatr. 2010; 99:354-358. [PubMed: 20064132]

3. Guillet R, Stoll BJ, Cotton CM, et al. Association of H2-blocker therapy and higher incidence of necrotizing enterocolitis in very low birth weight infants. Pediatrics. 2006; 117:e137-e142. [PubMed: 16390920]

4. Guyer B, Hoyert DL, Martin JA, Ventura SJ, MacDorman MF, Strobino DM. Annual summary of vital statistics-1998. Pediatrics. 1999; 104:1229-1246. [PubMed: 10585972]

5. Caplan MS, Jilling T. New concepts in necrotizing enterocolitis. Curr Opin Pediatr. 2001; 13:111115. [PubMed: 11317050]

6. Lin PW, Nasr TR, Stoll BJ. Necrotizing enterocolitis: Recent scientific advances in pathophysiology and prevention. Semin Perinatol. 2008; 32:70-82. [PubMed: 18346530]

7. Morgan JA, Young L, McGuire W. Pathogenesis and prevention of necrotizing enterocolitis. Curr Opin Infect Dis. 2011; 24:183-189. [PubMed: 21455063]

8. Graves SW. Sodium regulation, sodium pump function and sodium pump inhibitors in uncomplicated pregnancy and preeclampsia. Frontiers in Bioscience. 2007; 12:2438-2446. [PubMed: 17127253]

9. Hollenberg NK, Graves SW. Endogenous sodium pump inhibition: current status and therapeutic opportunities. Prog Drug Res. 1996; 46:9-42. [PubMed: 8754202]

10. Adair CD, Buckalew VM, Graves SW, Lam GK, Johnson DD, Saade G, Lewis DF, Robinson C, Danoff TM, Chauhan N, Hopoate-Sitake M, Porter KB, Humphrey RG, Trofatter KF, Amon E, Ward S, Kennedy L, Mason L, Johnston JA. Digoxin immune Fab treatment for severe preeclampsia. Amer J Perinatol. 2010; 27:655-662. [PubMed: 20232280]

11. Fedorova OV, Tapilskaya NI, Bzhelyansky AM, Frolova EV, Nikitina ER, Reznik VA, Kashkin VA, Bagrov AY. Interaction of Digibind with endogenous cardiotonic steroids from preeclamptic placentae. J Hypertens. 2010; 28:361-366. [PubMed: 19927009]

12. Hopoate-Sitake ML, Adair CD, Mason LA, Torres C, Kipikasa J, Graves SW. Digibind reverses inhibition of cellular $\mathrm{Rb}^{+}$uptake caused by endogenous sodium pump inhibitors present in serum and placenta of women with preeclampsia. Reproductive Sci. 2011; 18:190-199.

13. Ma J, Esplin MS, Adair CD, Mason LA, Graves SW. Increasing evidence for and regulation of a human placental endogenous digitalis-like factor. Reproductive Sci. 2112; 19:437-448.

14. Seccombe DW, Pudek MR, Whitfield MF, Jacobson BE, Wittmann BK, King JF. Perinatal changes in a digoxin-like immunoreactive substance. Pediatr Res. 1984; 18:1097-1099. [PubMed: 6514436]

15. Valdes R Jr. Graves SW, Brown BA, Landt M. Endogenous substances in newborn infants causing false-positive digoxin measurements. J Pediatrics. 1983; 102:947-950.

16. Sapia L, Palomeque J, Mattiazzi A, Petroff MV. $\mathrm{Na}^{+} / \mathrm{K}^{+}$-ATPase inhibition by ouabain induces CamKII-dependent apoptosis in adult rat cardiac myocytes. J Mol Cell Cardiol. 2010; 49:459-468. [PubMed: 20435043]

17. Ark M, Ozdemir A, Polat B. Ouabain-induced apoptosis and Rho kinase: a novel caspase-2 cleavage site and fragment of Rock-2. Apoptosis. 2010; 15:1494-1506. [PubMed: 20661774]

18. Xu ZW, Wang FM, Gao MJ, Chen XY, Hu WL, Xu RC. Targeting the $\mathrm{Na}(+) / \mathrm{K}(+)$-ATPase alpha 1 subunit of hepatoma HepG2 cell line to induce apoptosis and cell cycle arresting. Biol Pharm Bull. 2010; 33:743-751. [PubMed: 20460749]

19. Graves SW, Hopoate-Sitake M, Johnston A, Buckalew V, Lam G, Mason L, Adair D. Digoxin antibody fragment, antigen binding (Fab), treatment of preeclampsia in women with endogenous digitalis-like factor: a secondary analysis of the DEEP Trial. Amer J Obstet Gynecol. Apr 10.2013 ahead of print.

20. Rouse DJ, Hirtz DG, Thom E, et al. A randomized, controlled trial of magnesium sulfate for the prevention of cerebral palsy. N Engl J Med. 2008; 359:895-905. [PubMed: 18753646]

21. Zhen Y, Franz KB, Graves SW. A novel assay of cell rubidium uptake using graphite furnace atomic absorption: Application to rats on a magnesium deficient diet. J Nutritional Biochem. 2005; $16: 291-296$. 
22. Matsumori A, Ono K, Nishio R, Nose Y, Sasayama S. Amlodipine inhibits the production of cytokines induced by ouabain. Cytokine. 2000; 12:296-297.

23. Yu SP. $\mathrm{Na}^{+}, \mathrm{K}^{+}$-ATPase: the new face of an old player in pathogenesis and apoptotic/hybrid cell death. Biochem Pharmacol. 2003; 15:1601-1609. [PubMed: 14555240]

24. Ramani M, Ambalavanan N. Feeding practices and necrotizing enterocolitis. Clin Perinatol. 2013; 40:1-10. [PubMed: 23415260]

25. Karagol BS, Zenciroglu A, Okumus N, Polin RA. Randomized controlled trial of slow vs rapid enteral feeding advancements on the clinical outcomes of preterm infants with birth weight 750 1250 g. J Parenter Enteral Nutr. 2013; 37:223-228. 


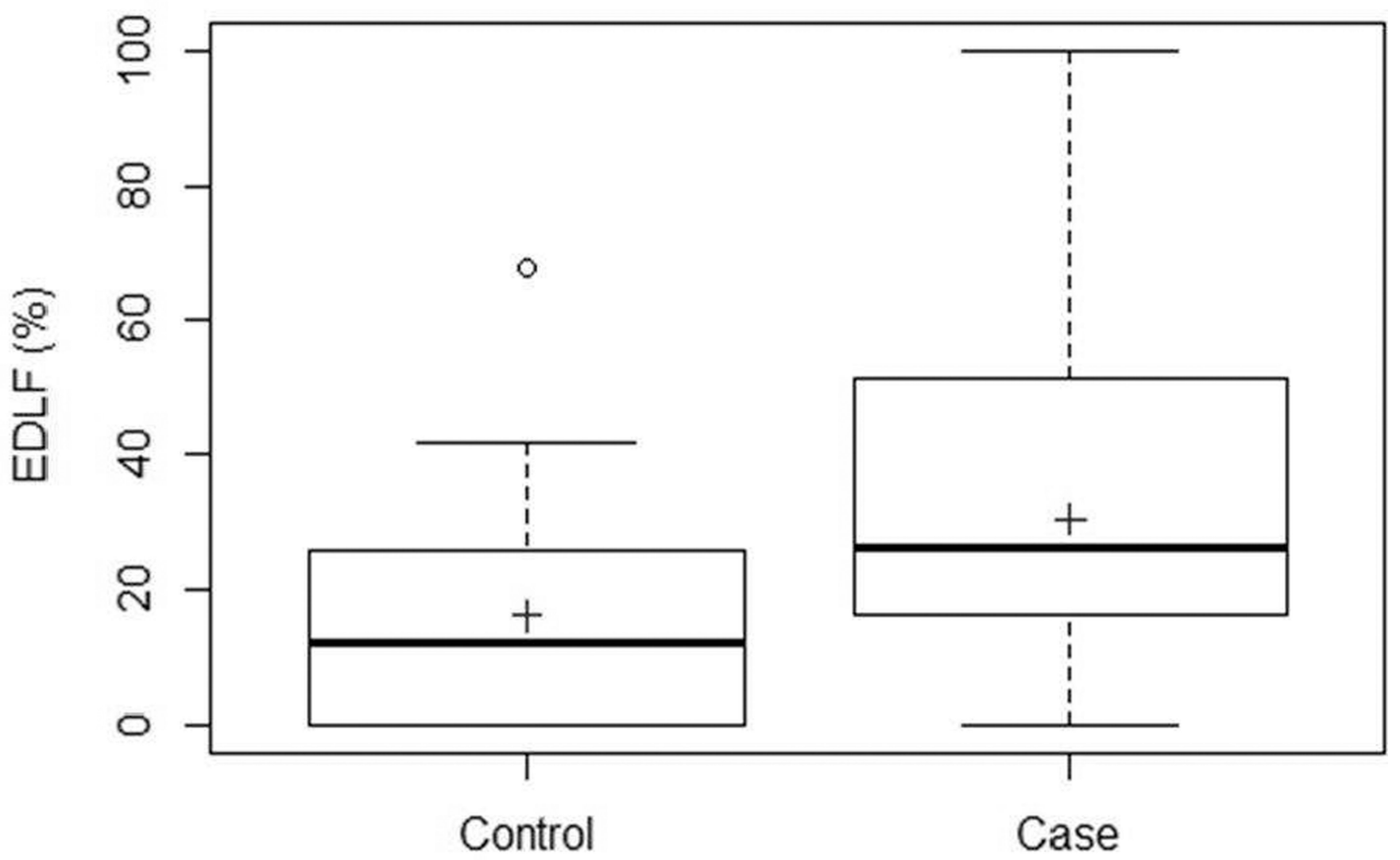

Figure 1.

Box plot of EDLF level versus clinical status. The cord serum levels of EDLF were plotted as a function of disease group, showing neonates used as controls (no BPD, NEC or IVH) and those developing stage 2 or 3 necrotizing enterocolitis (NEC). The "+" symbolizes the mean. 
Table 1

\section{Maternal Characteristics}

\begin{tabular}{|c|c|c|c|}
\hline & $\begin{array}{c}\text { Controls } \\
(\mathbf{N}=24)\end{array}$ & $\begin{array}{c}\text { NEC Cases } \\
(\mathbf{N}=\mathbf{2 5})\end{array}$ & p-value \\
\hline \multicolumn{4}{|l|}{ Race } \\
\hline African American & $13(54 \%)$ & $12(48 \%)$ & \multirow[t]{3}{*}{1.0} \\
\hline Hispanic & $3(12.5 \%)$ & $4(16 \%)$ & \\
\hline Caucasian & $8(33 \%)$ & $9(36 \%)$ & \\
\hline \multicolumn{4}{|l|}{ Labor type } \\
\hline Spontaneous & $13(54 \%)$ & $16(64 \%)$ & \multirow[t]{4}{*}{0.45} \\
\hline Induced & $7(29 \%)$ & $3(12 \%)$ & \\
\hline No labor & $2(8 \%)$ & $2(8 \%)$ & \\
\hline Spontaneous, augmented & $2(8 \%)$ & $4(16 \%)$ & \\
\hline Pre-eclampsia & $0(0 \%)$ & $0(0 \%)$ & $\mathrm{n} / \mathrm{a}$ \\
\hline Any maternal steroid use & $24(100 \%)$ & $25(100 \%)$ & $\mathrm{n} / \mathrm{a}$ \\
\hline PPROM & $23(96 \%)$ & $21(84 \%)$ & 0.35 \\
\hline Active treatment group (MgSO4) & $11(46 \%)$ & $13(52 \%)$ & 0.78 \\
\hline Gestational age at delivery (weeks) & $28 \pm 2$ & $28 \pm 2$ & 0.66 \\
\hline
\end{tabular}

Results are presented as means $\pm \mathrm{SD}$ or $\mathrm{N}(\%)$ 
Table 2

Neonatal Characteristics

\begin{tabular}{|l|c|c|c|}
\hline & $\begin{array}{c}\text { Controls } \\
(\mathbf{N}=\mathbf{2 4})\end{array}$ & $\begin{array}{c}\text { NEC Cases } \\
(\mathbf{N}=\mathbf{2 5})\end{array}$ & p-value \\
\hline Infant weight $(\mathrm{g})$ & $1177 \pm 295$ & $1200 \pm 366$ & 0.75 \\
\hline Female born & $11(46 \%)$ & $8(32 \%)$ & 0.39 \\
\hline Length of stay in NICU (days) & $40.9 \pm 27.4$ & $75.8 \pm 73.3$ & 0.058 \\
\hline
\end{tabular}

Results are presented as means \pm SD or N $(\%)$ 


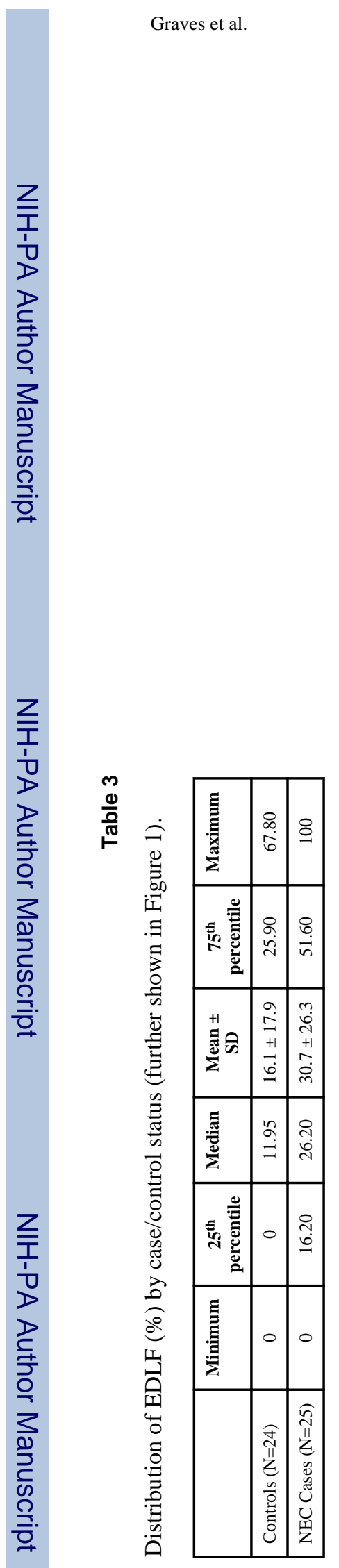

Page 12

Am J Obstet Gynecol. Author manuscript; available in PMC 2015 April 01. 
Table 4

EDLF Levels as a Function of NEC Severity

\begin{tabular}{|l|c|c|}
\hline & Mean $\mathbf{E D L F}(\boldsymbol{\%}) \pm \mathbf{S D}$ & \\
\hline No NEC & $15.7 \pm 17.5$ & 22 controls, no cases \\
\hline NEC level 1 & $20.9 \pm 29.6$ & 2 controls, no cases \\
\hline NEC level 2 & $20.1 \pm 22.0$ & 12 cases \\
\hline NEC level 3 & $40.5 \pm 26.9$ & 13 cases \\
\hline
\end{tabular}

Trend $\mathrm{p}=0.008$ 